\title{
Preparation of Activated Carbon Fibers from Cost Effective Commercial Textile Grade Acrylic Fibers
}

\author{
Mekala Bikshapathi ${ }^{1}$, Nishith Verma ${ }^{1, \star}$, Rohitashaw Kumar Singh ${ }^{2}$, \\ Harish Chandra Joshi ${ }^{2}$ and Anurag Srivastava ${ }^{2}$ \\ ${ }^{1}$ Depatment of Chemical Engineering, Indian Institute of Technology Kanpur, Kanpur-208016, India \\ ${ }^{2}$ Defence Materials and Stores Research \& Development Establishment, Kanpur-208013, India \\ ‘e-mail: nishith@iitk.ac.in \\ (Received January 18, 2011; Accepted March 7, 2011)
}

\begin{abstract}
Activated carbon fibers (ACFs) were prepared from cost effective commercial textiles through stabilization, carbonization, and subsequently activation by carbon dioxide. ACFs were characterized for surface area and pore size distribution by physical adsorption of nitrogen at $77 \mathrm{~K}$. ACFs were also examined for various surface characteristics by scanning electron microscopy, Fourier transform infrared spectroscopy, and CHNO elemental analyzer. The prepared ACFs exhibited good surface textural properties with well developed micro porous structure. With improvement in physical strength, the commercial textile grade acrylic precursor based ACFs developed in this study may have great utility as cost effective adsorbents in environmental remediation applications.
\end{abstract}

Keywords : Activated carbon fibers, Carbonization, Activation, Adsorption

\section{Introduction}

Activated carbon fibers (ACF) are porous carbon materials produced from a variety of fibrous carbonaceous precursors such as pitch fibers, polyacrylonitrile (PAN), phenolic resin, and viscose rayon [1-4]. In recent times, ACF has been used as a novel adsorbent having several advantages over the conventional forms of activated carbon, such as powders, granules, etc. [5-8]. The salient advantages include fast adsorption/desorption rate due to small fiber diameter, which minimizes diffusional resistance, flexibility of designing fibers in various forms like felts, paper, and nonwovens, ease of handling, abrasion resistance, and amenable to surface functionalization and also, regeneration [3].

It is needless to mention that the cost of precursor strongly affects the cost of the production of ACF. Hence, a lot of interest has been generated in recent years among researchers to reduce the cost of precursor so that the cost of $\mathrm{ACF}$ is low. In this context studies have been performed on preparation and characterization of $\mathrm{ACF}$ from the relatively less expensive textile grade acrylic fibers are available $[2,3,9,10]$.

In the present study, ACFs have been produced from the textile grade acrylic fibers through the steps comprising stabilization in air, carbonization in nitrogen $\left(\mathrm{N}_{2}\right)$, and activation in carbon dioxide $\left(\mathrm{CO}_{2}\right)$ atmosphere. The prepared ACFs have been characterized for surface textural properties, elemental analysis, surface morphology, and Fourier transform infrared spectroscopy (FTIR) analysis. The materials have potential to act adsorbents in environmental remediation applications.

\section{Experimental}

\subsection{Materials}

Commercial textile grade acrylic fibers (in non-carbonized/ non-activated form) were procured from $\mathrm{M} / \mathrm{s}$ Pasupati Acrylon Ltd., Moradabad, India. The $\mathrm{N}_{2}$, air, and $\mathrm{CO}_{2}$ gases (with the purity $>99 \%$ ) were obtained from Sigma Gases and Services Ltd., New Delhi, India.

\subsection{Methods}

The as-received non-carbonized and non-activated fibers were stabilized, carbonized and activated in a vertical tubular furnace having arrangement for suspending fibers in a quartz reactor $(\mathrm{ID}=3.5 \mathrm{~cm}, \mathrm{~L}=100 \mathrm{~cm})$. The arrangements were made for the gases (air, $\mathrm{N}_{2}$, and $\mathrm{CO}_{2}$ ) to flow through the reactor. Approximately 3.5-4.0 gm of acrylic fibers were placed in the reactor and stabilized at $230^{\circ} \mathrm{C}$ for five hours in air at the flowrate of 100 standard cc per min. The heating rate was maintained at $1^{\circ} \mathrm{C}$ per min. A load of approximately $80 \mathrm{gm}$ was applied during heating and taken off later before carbonization to overcome the shrinkage effect during 
stabilization. Carbonization in nitrogen atmosphere at heating rate of $2.5^{\circ} \mathrm{C}$ up to the desired activation temperature and subsequently activation in $\mathrm{CO}_{2}$ were carried out in a single step. The activation temperatures and times were varied from $700-950^{\circ} \mathrm{C}$ and $30-600 \mathrm{~min}$, respectively at constant $\mathrm{CO}_{2}$ flow rate. After activation all samples were cooled to room temperature in $\mathrm{N}_{2}$ atmosphere before removing from the reactor.

\subsection{Characterization}

The prepared ACFs were characterized for surface textural properties by the surface area analyzer (Micromeritics 2020 ASAP, USA). Before starting adsorption, the samples were outgassed at $300^{\circ} \mathrm{C}$ for $4 \mathrm{~h}$. The Brunauer-Emmett-Teller (BET) surface area and pore volume were calculated at $77 \mathrm{~K}$ using $\mathrm{N}_{2}$ as adsorbate. The BET equation was used for calculating surface area, and pore volume was measured with the help of adsorption isotherms at a relative pressure close to one, assuming that the pores are filled with liquid nitrogen (density $=0.808 \mathrm{cc} / \mathrm{g}$ ). Micropore volume was calculated by the t-plot method and the mesopore volume was calculated by the Barrett-Joyner-Halenda (BJH) method. Scanning electron microscopy (SEM) was carried out using Zeol scanning microscope (Germany) after plating samples with gold. The FTIR and elemental analysis were carried out using the Tensor 27 (Bruker, Germany) instrument and elemental analyzer (Model: CE-440 EL, Exeter Analytical Inc, USA), respectively.

\section{Results and Discussion}

\subsection{Activation process and surface textural properties}

The activation conditions and surface textural properties of acrylic fibers (indicated as F-Plain) and ACFs derived herein by activation using $\mathrm{CO}_{2}$ are summarized in Table 1 . It is evident from the table that relatively lower activation temperature has resulted into low surface area $\left(\sim 240 \mathrm{~m}^{2} / \mathrm{g}\right)$ of ACF (sample F24), even though the samples were activated for considerable time $(4 \mathrm{~h})$. However, increase in the activation temperature from $800^{\circ} \mathrm{C}$ to $900^{\circ} \mathrm{C}$ resulted in the significant increase of surface area from $240 \mathrm{~m}^{2} / \mathrm{g}$ to $734 \mathrm{~m}^{2} / \mathrm{g}$. With further increase in the activation temperature above $900^{\circ} \mathrm{C}$, the surface area decreased.

Porosity in carbon materials initially develops during carbonization due to irregular spacing between aromatic sheets. However, the pores are subsequently blocked-off because of deposition of tarry materials. Activation is aimed at partial gasification of carbonized materials in order to clear off disorganized carbon and open up closed pores, and at the same time creating new pores by selective burning off of the carbon atoms from regions of low energy [11]. Therefore, the observed increase of surface area as well as pore volume in the present case is attributed to the gasification of carbonized fibers by $\mathrm{CO}_{2}$. At low activation temperature the micropore formation and the pore widening occur simultaneously, resulting in a large micro porous and low surface area-carbon. This is probably the reason for low surface area and high micro porosity observed for the sample F24. Moreover, at low temperature pore widening does not commence and in addition, the creation of new pores occurs at a slow rate. This may also be attributed to the slow reaction rate of $\mathrm{CO}_{2}$ with the carbonized fibers. At relatively higher activation temperatures both pore formation and widening occur. However, creation of pores occurs at a slower rate as compared to that of pore widening [4]. This explains decrease in micro porosity observed in the sample F17. At high activation temperature $\left(950^{\circ} \mathrm{C}\right)$, the reaction of $\mathrm{CO}_{2}$ with carbonized fibers occurs at large rate resulting in surface oxidation rather than gasification inside the carbon skeleton. The reason may be attributed to the collapse of micro porous structure because of the thermal shrinkage of pores at high temperature, as also reported elsewhere [12,13].

Sample F19 exhibited poor physical strength on physical observation suggesting the adverse effect of reaction at $950^{\circ} \mathrm{C}$. Comparing the surface characteristics of different samples, the activation conditions used in preparing the sample F4 appear optimum, as the corresponding ACFs have reasonable large surface area and micro porosity. It appears that the optimum reaction conditions facilitate a balance

Table 1. Surface Areas, Pore Volumes, and Pore Size Distributions of the Different Samples

\begin{tabular}{ccccccccccc}
\hline S. No Sample & $\begin{array}{c}\text { Activation } \\
\text { temperature } \\
\left({ }^{\circ} \mathrm{C}\right)\end{array}$ & $\begin{array}{c}\text { Activation } \\
\text { time }(\mathrm{min})\end{array}$ & $\begin{array}{c}\text { BET surface } \\
\text { area }\left(\mathrm{m}^{2} / \mathrm{g}\right)\end{array}$ & $\begin{array}{c}\text { Micro pore } \\
\text { area }\left(\mathrm{m}^{2} / \mathrm{g}\right)\end{array}$ & $\begin{array}{c}\text { Total pore } \\
\text { volume } \\
(\mathrm{cc} / \mathrm{g})\end{array}$ & $\begin{array}{c}\text { Micro pore } \\
\text { volume } \\
(\mathrm{cc} / \mathrm{g})\end{array}$ & $\begin{array}{c}\text { Micro } \\
\text { porosity } \\
(\%)\end{array}$ & $\begin{array}{c}\text { Meso pore } \\
\text { volume } \\
(\mathrm{cc} / \mathrm{g})\end{array}$ & $\begin{array}{c}\text { Meso } \\
\text { porosity } \\
(\%)\end{array}$ \\
\hline 1 & F-plain & -- & -- & -- & -- & -- & -- & -- & -- & -- \\
2 & F-24 & 750 & 300 & 240 & 226 & 0.139 & 0.133 & 95 & 0.006 & 4 \\
3 & F-9 & 800 & 180 & 330 & 293 & 0.26 & 0.241 & 92 & 0.019 & 7 \\
4 & F-4 & 850 & 180 & 654 & 634 & 0.359 & 0.332 & 92 & 0.027 & 7 \\
5 & F-17 & 900 & 90 & 734 & 616 & 0.46 & 0.314 & 68 & 0.146 & 31 \\
6 & F-19 & 950 & 30 & 472 & 416 & 0.275 & 0.212 & 77 & 0.063 & 22 \\
\hline
\end{tabular}

BET: Brunauer-Emmett-Teller. 


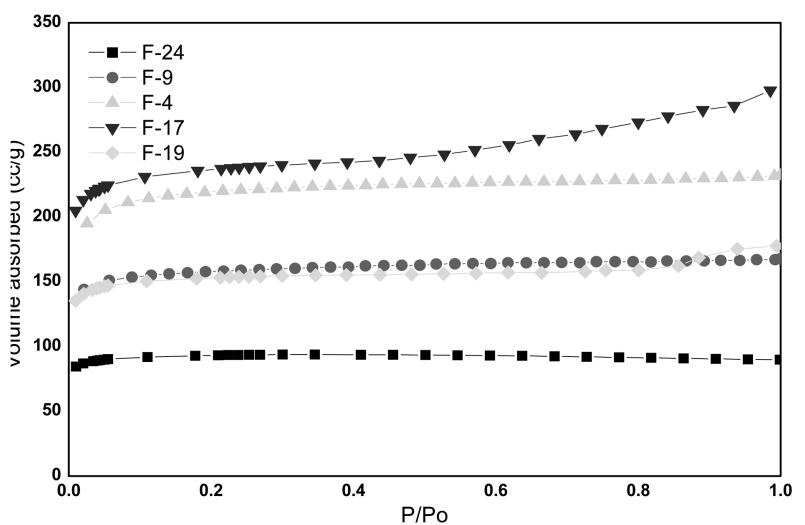

Fig. 1. Nitrogen adsorption isotherms at $77 \mathrm{~K}$ of F-24 (activated at $750^{\circ} \mathrm{C}, 300 \mathrm{~min}$ in $\mathrm{CO}_{2}$ atmosphere), F-19 (activated at $950^{\circ} \mathrm{C}, 30 \mathrm{~min}$ in $\mathrm{CO}_{2}$ atmosphere), $\mathrm{F}-17$ (activated at $900^{\circ} \mathrm{C}$, $90 \mathrm{~min}$ in $\mathrm{CO}_{2}$ atmosphere), F-19 (activated at $950^{\circ} \mathrm{C}, 30 \mathrm{~min}$ in $\mathrm{CO}_{2}$ atmosphere), F-9 (activated at $800^{\circ} \mathrm{C}, 180 \mathrm{~min}$ in $\mathrm{CO}_{2}$ atmosphere), F-4 (activated at $850^{\circ} \mathrm{C}, 180 \mathrm{~min}$ in $\mathrm{CO}_{2}$ atmosphere).

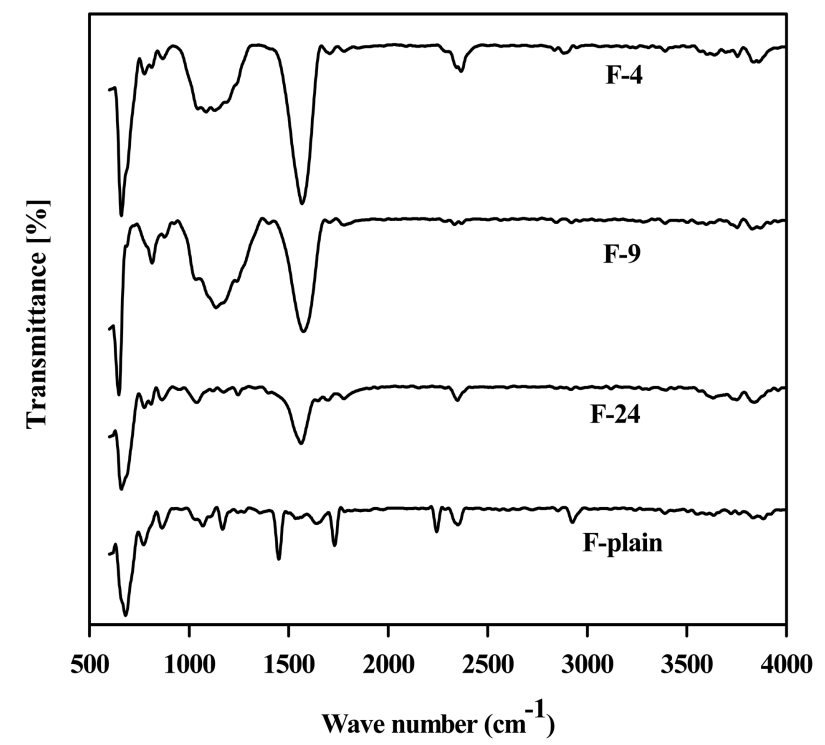

Fig. 2. Fourier transform infrared spectroscopy analysis of different samples.

between pore creation (leading to micro pores) and pore widening (leading to mesopores), as observed fin sample F4. It is worthwhile to point out here that a balance between the micropores formation and destruction (pore widening) leads to the development of a viable commercial adsorbent which is the primary objective of this study.

\subsection{Adsorption isotherms}

Adsorption by nitrogen at $77 \mathrm{~K}$ is a standard procedure for the characterization of porous materials. The shape of nitrogen adsorption isotherm provides information about the development of porosity in adsorbents. As per International Union of Pure and Applied Chemistry (IUPAC) norms pores are classified in three categories according to the pore dimensions: (a) micro pores (average size $<2 \mathrm{~nm}$ ) (b) meso pores $(2 \mathrm{~nm}<$ average size $<50 \mathrm{~nm})$, and (c) macro pores (average size $>50 \mathrm{~nm}$ ) [14]. The isotherms for ACF (Fig. 2) are observed to be type 1 , which is the characteristics of micro porous adsorbents, according to Brunauer, Deming, Deming and Teller (BDDT) classification [15]. The shapes of such isotherms have a platue after an initial vertical rise. The knees of the isotherms are sharp and the platues are fairly horizontal. It implies that the pore size distribution is narrow. This is also supported by the high porosity values, as indicated in Table 1. However, increased adsorption is observed at high relative pressures for samples F17 and F19. This indicates that the sample is micro porous having a relatively smaller external surface area, which may be because of widening of the existing micro pores. As discussed in section 3.1, the isotherms also reflect activation and the development of porosity in ACFs. It is evident that the pore formation overrates pore widening below $850^{\circ} \mathrm{C}$. A highly micro porous ACF is consequently produced, as reflected in the corresponding adsorption isotherm with an initial rise in the slope. The slope tends to level off at high relative pressures. However, pore widening above $850^{\circ} \mathrm{C}$ takes place at a faster rate in comparison to that of the formation of new pores. This is reflected in the shape of isotherms (sample F17) with an increase in slope at high relative pressures.

\subsection{Elemental analysis}

The acrylic fibers (in non-carbonized and non-activated forms, represented as F-Plain) and ACFs were analyzed for elemental compositions for carbon $(\mathrm{C})$, hydrogen $(\mathrm{H})$, nitrogen $(\mathrm{N})$, and oxygen $(\mathrm{O})$. As observed from the Table 2, there is continually marginal increase of C-contents, which is an indicative of increased charring of base material at high temperature. On contrary, $\mathrm{N}$ - and $\mathrm{H}$-contents significantly decrease with increasing activation temperature. O-contents increase continually. The reason is attributed to the reaction between the activating agent and carbon matrix, producing oxygenated functional groups, also corroborated by the FTIR spectra discussed later in the manuscript. Therefore, it may be concluded that $\mathrm{CO}_{2}$ activation results in increase of $\mathrm{O}$-contents.

Table 2. Elemental Analysis Data

\begin{tabular}{cccccc}
\hline \multirow{2}{*}{ S. No } & \multirow{2}{*}{ Sample } & \multicolumn{4}{c}{ Elemental data (wt \%) } \\
\cline { 3 - 6 } & & $\mathrm{C}$ & $\mathrm{H}$ & $\mathrm{N}$ & $\mathrm{O}$ \\
\hline 1 & F-plain & 65.51 & 5.63 & 22.85 & 4.96 \\
2 & F-24 & 71.10 & 1.03 & 12.10 & 13.15 \\
3 & F-9 & 71.47 & 0.87 & 8.96 & 16.92 \\
4 & F-4 & 73.15 & 0.74 & 6.40 & 18.36 \\
\hline
\end{tabular}




\subsection{FTIR analysis}

All samples except F-plain were treated with $\mathrm{CO}_{2}$ at different temperatures. The corresponding FTIR spectra are shown in Fig. 2. As observed, the small peaks at around $1700-1785 \mathrm{~cm}^{-1}$ are due to the carbonyl functionality of different groups such as ketone, lactone, aldehyde, and quinine on the carbon surface. The aromatic C-C stretching observed at around $1550 \mathrm{~cm}^{-1}$ is because of activation at high temperature, as the disordered carbon are arranged and aromatized. The peaks observed between 950 to $1350 \mathrm{~cm}^{-1}$ for high temperatures-activated samples correspond to the $\mathrm{C}$ $\mathrm{O}$ stretching of alcohols, carboxylic acids, esters, ethers, and lactone, and also to the aromatic $\mathrm{C}-\mathrm{H}$ bending or deformation. In summary, it may be concluded that the surface gets increasingly ordered at high temperature.

\subsection{SEM observation}

The SEM images of non-carbonized, non-activated acrylic precursor fiber, carbonized fiber and ACF are shown in Fig. 3. The images shown in Figs. 3(a) and (b) are suggestive of the preservation of the initial structure of acrylic fiber during stabilization and carbonization. Similar observation has also been reported in a study [2]. As also observed in Fig. 3(a), the cross-section of non-carbonized and non-activated fiber is kidney shaped. The diameter of carbonized fiber is around 10-12 $\mu \mathrm{m}$, as observed in Fig. 3(b). We also examined electron micrographs both at cross-sections and along the surface. Small unevenly dispersed pits on surface were observed in ACFs, as shown in Figs. 3(c) and (d). In the SEM investigation carried out by Ryu et al. [3], elongated

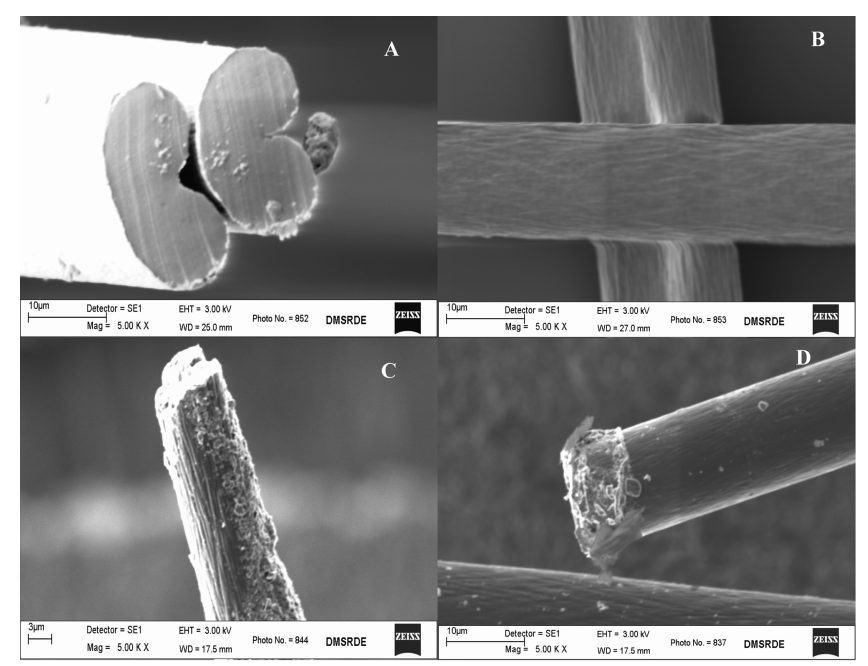

Fig. 3. SEM images of F-plain, F-carbonized $\left(850^{\circ} \mathrm{C}, 30 \mathrm{~min}\right.$ under $\mathrm{N}_{2}$ flow), $\mathrm{F}-17$ (activated at $900^{\circ} \mathrm{C}, 90 \mathrm{~min}$ in $\mathrm{CO}_{2}$ atmosphere), and F-19 (activated at $950^{\circ} \mathrm{C}, 30 \mathrm{~min}$ in $\mathrm{CO}_{2}$ atmosphere). SEM: scanning electron microscopy. micro pores created because of shear during spinning were observed parallel to the fiber axis. The similar pores were, however, not observed in the present investigation. It appears from the surface morphology of sample F-19 that $\mathrm{CO}_{2}$ gasification rate at $950^{\circ} \mathrm{C}$ is high, resulting in surface roughening and fiber disintegration. Similar observations are also reported elsewhere $[2,10]$.

\section{Conclusions}

ACFs were produced from the cost effective commercially available textile grade acrylic fibers. The ACFs showed good surface textural properties and physical strength at relatively lower activation temperatures. However, activation at higher temperature produced ACFs with small surface area and micro porosity. The ACFs showed physical disintegration as well as small surface area and micro porosity above $900^{\circ} \mathrm{C}$. The activation temperature of $850^{\circ} \mathrm{C}$ and activation time of $180 \mathrm{~min}$ were found to be optimum for producing ACFs having the BET surface area of $654 \mathrm{~m}^{2} / \mathrm{g}$ and pore volume of $0.359 \mathrm{cc} / \mathrm{g}$. ACFs produced may be of great interest as a cost effective adsorbent material in various adsorption applications. However, physical strength of ACF is required to be improved upon for commercial viability.

\section{References}

[1] Ryu SK, Kim SY, Gallego N, Edie DD. Carbon, 37, 1619 (1999).

[2] Carrott PJM, Nabais JMV, Ribeiro Carrott MML, Pajares JA. Carbon, 39, 1543 (2001).

[3] Ryu Z, Zheng J, Wang M. Carbon, 36, 427 (1998).

[4] Gurudatt K, Lal D, Tripathi VS. Indian J Fiber Textil Res, 23, 153 (1998).

[5] Oya A, Yoshida S, Alcaniz-Monge J, Linares-Solano A. Carbon, 34, 53 (1996).

[6] Li CY, Wan YZ, Wang J, Wang YL, Jiang XQ, Han LM. Carbon, 36, 61 (1998).

[7] Bohra JN, Saxena RK. Colloid Surface, 58, 375 (1991).

[8] Oya A, Yoshida S, Alcaniz-Monge J, Linares-Solano A. Carbon, 33, 1085 (1995).

[9] You SY, Park YH, Park CR. Carbon, 38, 1453 (2000).

[10] Carrott PJM, Nabais JMV, Ribeiro Carrott MML, Pajares JA. Fuel Process Technol, 77-78, 381 (2002).

[11] Marsh H, Rand B. Carbon, 9, 47 (1971).

[12] Nakagawa H, Watanabe K, Harada Y, Miura K. Carbon, 37, 1455 (1999).

[13] Carrott PJM, Freeman JJ. Carbon, 29, 499 (1991).

[14] Zdravkov BD, Cermak JJ, Sefara M, Janku J. Cent Eur J Chem, 5, 385 (2007).

[15] Gregg SJ, Sing KSW. Adsorption, Surface Area, and Porosity. 2nd ed., Academic Press, New York (1982). 